\title{
Mantispa styriaca (Poda, 1761) (Neuroptera: Mantispidae) in Romania - a New Record After a Half of Century
}

\author{
Ioan TĂUŞAN ${ }^{1,}$, , Mădălin POPESCU ${ }^{1}$, Alexandru PINTILIOAIE ${ }^{2}$ \\ 1"Lucian Blaga" University of Sibiu, Faculty of Sciences, Applied Ecology Research Centre, Dr. Raţiu \\ 5-7, 550012, Sibiu, Romania \\ 2"Alexandru Ioan Cuza” University, Faculty of Biology, Carol I Blvd. 20A, 700505 Iaşi, Romania \\ *corresponding author, e-mail: itausan@gmail.com
}

Received: November 23, 2017; Accepted: February 12, 2018; Available online: March 16, 2018; Printed: June 30, 2018

\begin{abstract}
The Romanian fauna of mantispids (Neuroptera: Mantispidae) is represented by two species, at least. Data on the distribution of both species is relatively scarce. Mantispa styriaca (Poda, 1761) is considered an expansive holomediterranean element. Herein, we report a new record of the species after a half of century. Insights regarding the species ecology are given.
\end{abstract}

Key words: mantispids, wood-pastures, oak, faunistics, Transylvania.

Mantispidae (Leach, 1815) is a small cosmopolitan family belonging to the highly diverse order Neuroptera. The genus Mantispa Illiger, 1798, was described, more than two centuries ago, with the type species Mantis pagana Fabricius, 1775 [= Mantispa styriaca (Poda, 1761)].

The genus Mantispa became the best-known within the Mantispidae family, probably due to the age of the genus, several species being described worldwide and incorrectly assigned to this genus (Snyman et al. 2012). Moreover, many studies (Lambkin, 1986; Hoffman, 2002; Machado \& Rafael, 2010; Snyman et al., 2012) suggest that Mantispa's distribution includes the Old World, with few Palaearctic and Oriental species. The species identification relies on several morphological characters, such as: the ventral colour of the femurs of the first pair of legs being completely brown, without yellow spots, the wings which are transparent (with no yellowish or brownish colour), with proximally clear and distally strongly widen pterostigma (Aspöck \& Aspöck, 1994).

In Europe, the genus is represented by several species: Mantispa incorrupta Monserrat, 2014, M. aphavexelte Aspock \& Aspock, 1994, M. scabricollis McLachlan, 1875, M. perla Pallas, 1772 and M. styriaca (Poda, 1761). The latter two species may occur in Romania (Kis et al., 1970). However, in the catalogue of the Neuropterida of the Western Palearctic (Aspöck et al., 2001), only M. styriaca is regarded as present in Romania. Moreover, given the taxonomic history of Mantispa aphavexelte (see Aspöck \& Aspöck, 1994) and the fact that the drawings of Mantispa perla from the Kis's book are actually of Mantispa aphavexelte (Davide Badano, personal communication), it's highly probable that this last species also occurs in Romania. Further studies on the previously collected material of Mantispa perla from Romania will shed light on this topic.

Mantispa styriaca is one of the most common species of the family Mantispidae in the Mediterranean region. Its distribution is known also from Western Asia and Mongolia (Duelli et al., 2015). In Romania, the species is known only from few locations: 
Sibiu, Cluj and Băile Herculane (Kis et al., 1970). However, in the distribution map of the Mantispa species for Romania (Kis et al., 1970), the latter location is missing. Herein, we report a new record of the species after a half of century.

The material ( 1 female) was collected using yellow pant traps (installed in the canopy, 3 meters high) near Crăciunel $\left(46.1298^{\circ} \mathrm{N}, 25.418^{\circ} \mathrm{E}, 520 \mathrm{~m}\right.$ a.s.l) (Harghita County, Romania), on 20.06.2016. The specimen is deposited in the personal collection of Alexandru Pintilioaie.

Mantispa styriaca is known to be a kleptoparasite in cocoons of wolf spiders (Gepp, 1986) and it is considered an expansive holomediterranean and xerothermic element (Kis et al., 1970; Ábraham \& Papp, 1994). Based on Kis et al. (1970), the species prefers deciduous forest edges, bushes and trees, mainly in the hilly areas. According to Monserrat (2014), the species can be found mostly in sunny areas, usually avoiding wooded and shady places. It has been collected mainly on mature and isolated oak trees, although it seems to be no direct relationship between the tree and the insect. Moreover, it may seem that adults can be found between May-September and between 100-2000 $\mathrm{m}$ a.s.l.. In our case, we collected the species from the canopy of a solitary oak in a pasture.

Increasing the sampling effort in more habitats across the country it may be revealed that the species is more frequent as it was previously assumed.

\section{ACKNOWLEDGEMENTS}

We are grateful to Sergiu Blezu and Ionică Muraru for their help in the field campaigns. We are also indebted to Davide Badano, Roberto Pantaleoni and Alexi Popov for their useful advice on the taxonomy of Mantispa species. Finally, we would like to express our sincere gratitude to the anonymous referees for their helpful comments which improved the early version of the manuscript. Financial support was received through the project 'Oak woods in rural landscapes of the Carpathian region: origin, dynamics and conservation values', financed by the National Science Centre, Poland, following the decision DEC-2013/11/B/NZ9/00793.

\section{REFERENCES}

ÁBRÁHAM, L., Z. PAPP (1994) Mantispids species in the Hungarian fauna with some taxonomical remarks (Neuroptera: Mantispidae). Folia Historico Naturalia Musei Matraensis, 19: 69-75.

ASPÖCK, U., H. ASPÖCK (1994) Zur Nomenklatur der Mantispiden Europas (Insecta: Neuroptera: Mantispidae). Annalen des Naturhistorischen Museums in Wien, 96 B: 99-114. (in German)

ASPÖCK H., H. HÖLZEL, U. ASPÖCK (2001) Kommentierter Katalog der Neuropterida (Insecta: Raphidioptera, Megaloptera, Neuroptera) der Westpaläarktis. Denisia 2: 1-606. (in German)

DUELLI, P., D. BOLT, C. S. HENRY (2015) Neuroptera of the Caucasian Republic of Georgia. Entomological news, 124 (4): 229-244.

GEPP, J. (1986) Biology and larval diagnosis of central European Neuroptera (A review of present knowledge). In: Gepp, J, H. Aspöck, H. Hölzel (eds.), pp. 137-144, Graz.

HOFFMAN, K. M. (2002) Family Mantispidae. In: Penny N. D. (ed.) A guide to the lacewings (Neuroptera) of Costa Rica. Proceedings of the California Academy of Sciences, 53: 251-275.

KIS, B., C. NAGLER, C. MÂNDRU (1970) Neuroptera (Planipennia). In: Fauna R. P. R. Insecta. Edit. Academiei R. P. R., 8 (6), 346 pp. (in Romanian)

LAMBKIN, K. J. (1986) A revision of the Australian Mantispidae II (Insecta: Neuroptera) with a contribution to the classification of the family II. Calomantispidae and Mantispidae. Australian Journal of Zoology, 1-113. doi: 10.1071/ajzs117

MACHADO, R. J. P., J. A. RAFAEL (2010) Taxonomy of the Brazilian species previously placed in Mantispa Illiger, 1798 (Neuroptera: Mantispidae), with the description of three new species. Zootaxa, 2454(1): 1-61.

MONSERRAT, J. V. (2014) Revisión de los mantíspidos de la Península Ibérica y Baleares (Insecta, Neuropterida, Neuroptera, Mantispidae). Graellsia, 70(2): e012: 1-52. (in Spanish)

SNYMAN, L. P., M. OHL, M. W. MANSELL, C. H. SCHOLTZ (2012) A revision and key to the genera of Afrotropical Mantispidae (Neuropterida, Neuroptera), with the description of a new genus. ZooKeys, (184): 67-93. 